\title{
Study and Optimization of a Renewable System of Small Power Generation
}

\author{
Mohammed Salim Hadjidj, Nacer-Eddine Bibi-Triki, Faouzi Didi \\ Department de physique Unite de Recherche Materiaux et Energies Renouvelables (URMER), \\ Tlemcen, Algerie
}

\begin{tabular}{l} 
Article Info \\
\hline Article history: \\
Received May 6, 2018 \\
Revised May 17, 2018 \\
Accepted May 27, 2018 \\
\hline Keyword: \\
Hybrid Photovoltaic \\
Optimization. \\
Photovoltaic System \\
Sizing \\
Storage System \\
Wind \\
Wind System
\end{tabular}

\begin{abstract}
In this paper, a study was conducted on the sustainable development of solar and wind energy sources. The approach adopted is to exploit the two renewable resources by arriving to determine optimal configurations of photovoltaic and / or wind energy system with storage to provide electricity to a self-contained residential apartment located in the city of Tlemcen , in Algeria. The Tlemcen site showed a more favourable trend to use the photovoltaic system alone on the hybrid PV / wind system because of the low wind speeds of this site. The calculation method used is based on the monthly averages for ten consecutive years, data collected by the Tlemcen Zenâta weather station in order to have a better reliability analysis of an electric power generation system. In addition, the methods used in this study can be used to determine the optimal size of the most economical hybrid system that corresponds to any site in the world and for any requested load.
\end{abstract}

Copyright (C) 2018 Institute of Advanced Engineering and Science. All rights reserved.

Corresponding Author:

Mohammed Salim Hadjidj,

Department de physique

Unite de Recherche Materiaux et Energies Renouvelables (URMER),

Tlemcen, Algerie.

Email: m.salimhadjidj@gmail.com

\section{INTRODUCTION}

Man has always had increasing energy needs all over the world. Consequently, energy consumption is increasing as a result of economic growth and an increase in electricity consumption per inhabitant. To this end, the developing countries will be in need of energy to ensure their development although the use of fossil energy will have a negative impact on their environment thus making it necessary to use renewable energies for a healthy and sustainable energetic transition. Algeria has available one of the most important solar potential in the world. Sunshine duration in almost all the territory exceeds 2000 hours a year reaching 3900 hours in the high plateaus and the Sahara. The energy received daily on a horizontal surface of $1 \mathrm{~m}^{2}$ is in the order of $5 \mathrm{kwh}$ in most parts of the territory, being about $17 \mathrm{kWh} / \mathrm{m}^{2} /$ year in the north and $2650 \mathrm{kWh} / \mathrm{m}^{2} /$ year in the south of the country [1]. Algeria also has available a considerable wind energy whose potential is particularly important in the south with average speeds of 4 to $6 \mathrm{~m} / \mathrm{s}$; a priceless resource that can meet domestic needs in remote areas while the north is less windy with the exception of microclimates in the coastal region of Oran and Bedjaia and the areas of Tiaret, Biskra and Setif [1], [3]. The exploitation of the potential of renewables (photovoltaic, wind) of isolated places distant from conventional networks of power supply must stand as a priority due to the financial cost caused by the installation of a conventional electric network. Yet, one must not lose sight of the weather and topographic variation which must be taken into account.

The photovoltaic energy cannot be a continuous source of energy because of its low availability in winter. Likewise, wind energy is greatly irregular in time and cannot produce energy constantly. Therefore, the separate use of these two sources presents problems with regard to energy requirements. To solve the previously mentioned problems, and to study an energy system that will supply electricity to a self-contained 
apartment located in Tlemcen in Algeria for a reference year, a photovoltaic and / or wind energy system with storage is suggested. This system generates simultaneously energy from the absorbed solar energy and the captured wind energy that can be consumed directly or stored in batteries whose role is to ensure the continuity of use. Nevertheless, developing a cost-effective system includes design issues such as the dimensioning of the correct size of each component and the economic optimisation of the cost of the generated kWh. The purpose of this article is to show the reliability of using the electrical energy of solar and / or wind resources to meet the needs of a requested electrical load. A thorough study is used to find the best energy system configuration while presenting the results of sunray measurements, wind speeds, and energy data generated by the modules photovoltaic or wind turbines and storage that varies according to days of autonomy. The system obtained aims to supply a charge for domestic use (apartment) where consumption is about 3,260 kWh per day (September-May) and 9,150 a day (July-August).

\section{SITE DESCRIPTION AND ASSESSMENT OF SOLAR AND WIND RESOURCES AND REQUIRED CHARGE \\ 2.1. Studied Site}

The selected site is located in Tlemcen in a region of Zenâta in Algeria. The characteristics of the site are displayed on the Table 1.

Table 1. Characteristics of the Zenâta Site [2]

\begin{tabular}{ccccc}
\hline Site & Latitude & Longitude & Altitude & Albédo \\
\hline Tlemcen & $35.02^{\circ} \mathrm{N}$ & $1.18^{\circ} \mathrm{E}$ & $247 \mathrm{~m}$ & 0.20 \\
\hline
\end{tabular}

\subsection{Assessment of the Solar and Wind Resources}

It is crucial to define and specify the data of local resources (solar irradiation and wind speed) of the selected region. This study is based on a daily data source of two sources, solar and wind energy, measured at a height of $10 \mathrm{~m}$ above ground level for 12 months and year-round for 10 years ( 2000 - 2010). Data were obtained from the Tlemcen Zenata meteorological station METAR / SYNOP [3].

a) Solar resource

Figure 1 shows the monthly average of each year of the solar radiation index of the region of Tlemcen.

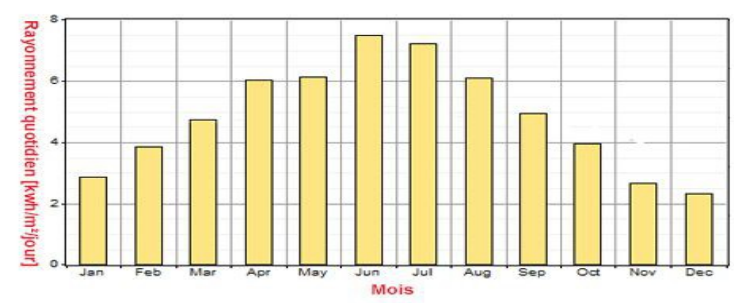

Figure 1. Monthly sun radiation of the tlemcen site

The solar radiation in Tlemcen reaches its minimum of $2.3 \mathrm{kWh} / \mathrm{m}^{2} /$ day in December and its maximum of $7.5 \mathrm{kWh} / \mathrm{m}^{2} /$ day in June, and the annual average is $4.8 \mathrm{kWh} / \mathrm{m}^{2} /$ day.

b) Wind resource

Figure 2 represents the monthly average of each year of wind speeds of the region of Tlemcen. 


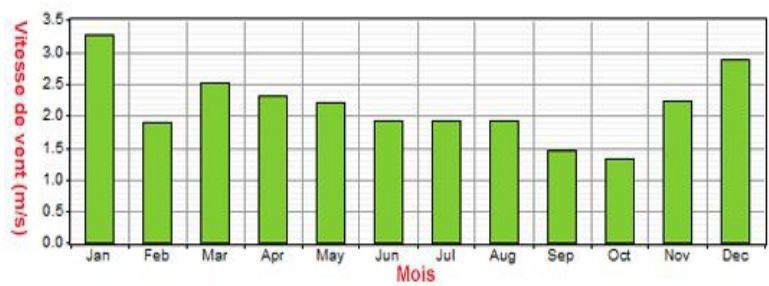

Figure 2. Monthly wind speeds of the tlemcen site

The wind speeds are considered as relatively weak throughout the year. January being the most windy month with a wind speed of 3, $2 \mathrm{~m} / \mathrm{s}$ and October the least windy of the year with a speed of 1,3 m/s. The annual wind speed average for the site in Tlemcen over the study period.

c) Temperature

Table (2) shows the monthly average if each year of temperature for the region of Tlemcen.

Table 2. Monthly Temperature Average

\begin{tabular}{ccccccccccccccc}
\hline Month & Jan & Feb & Mar & Apr & Mai & Jun & Jul & Aug & Sep & Oct & Nov & Dec & $\begin{array}{c}\text { Annual } \\
\text { average }\end{array}$ \\
\hline $\begin{array}{c}\text { Temperature } \\
\left(\mathrm{c}^{\circ}\right)\end{array}$ & 6.27 & 8.23 & 11.6 & 14.8 & 19.9 & 25.4 & 28.9 & 28.0 & 23.1 & 17.6 & 11.7 & 7.65 & 17.0 \\
\hline
\end{tabular}

The monthly temperature average reaches its minimum in January estimated to $6.27^{\circ} \mathrm{C}$ and its maximum to $28.9^{\circ} \mathrm{C}$ in July and the annual average is $17^{\circ} \mathrm{C}$. These temperatures will not affect the operation of convertors in the photovoltaic installation or wind turbines.

\subsection{Characteristics of the Selected Apartment and its Energy Balance}

The apartment chosen for the study is of type not connected to the conventional power distribution network and equipped with all the devices to provide comfort to the occupants. In addition, it is permanently occupied throughout the year and the domestic equipment operates under a standard voltage $220 \mathrm{~V}-50 \mathrm{~Hz}$ (mains voltage). The daily consumption is supposed constant during the nine following months (SeptemberMay) in the order of 3,260 KWh per day and another constant value during the summer season (June, July, and August) estimated at 9,150 KWh per day, the daily energy needs of the apartment by Wh/day are shown on the Table (3)[4].

Table 3. Assessment of Daily Energy Needs of Apartment

\begin{tabular}{ccccc}
\hline & Power(w) & $\begin{array}{c}\text { Duration of use } \\
\text { (hours) }\end{array}$ & Daily consumption (Wh) \\
\hline \multirow{5}{*}{ Lighting } & Adults' room & 11 & 4 & 44 \\
& Children's room & 22 & 5 & 110 \\
& Living room & 22 & 6 & 132 \\
& Corridor & 22 & 2 & 44 \\
& Bathroom & 22 & 2 & 44 \\
& Toilets & 11 & 1 & 77 \\
Appliances & 11 & 7 & 96 (winter), 1440 (summer) \\
& Kitchen & 120 & 8 (winter), 12 (summer) & 397.26 \\
& Refrigerator & 5 Th30 & 0 (winter), 6600 (summer) \\
& Air conditioner & 3663 & 0 (winter), 6 (summer) & 250 \\
& Others & 100 & 2 & $3260 / 9150$ \\
\hline
\end{tabular}

Figure 3 shows the total consumption of the apartment in one typical day in the winter season (September-May): 3,260 kWh in 24 hours. Figure 4 shows the total consumption of the apartment in one day in the summer season,(June-August): 9,150KWh in 24 hours. 


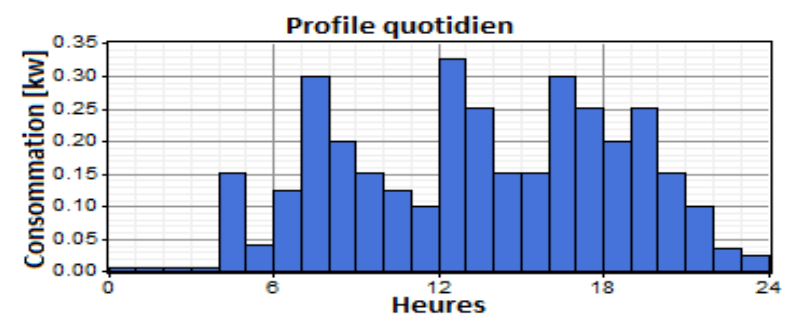

Figure 3. Daily profile (winter season)

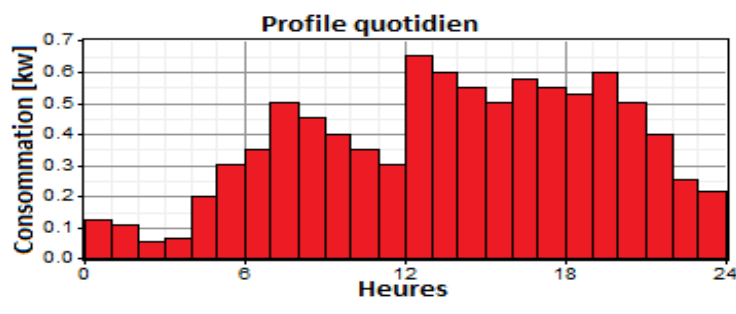

Figure 4. Daily profile (summer season)

\section{METHODS}

The crucial stage in the conception of a power generation system is determining its optimal size which depends essentially on the climatic data of the site and the characteristics of the parameters contained in this system.

This part discusses the models used in the study to determine the optimal size of the electric power generation system that can meet the electrical needs of the apartment.

\subsection{Global Incoming Solar Radiation and Energy Produced by the Photovoltaic Generator}

The global incoming solar radiation in a photovoltaic panel according to the HDKR (Hay, Davies, Klucher, Reindl) model [5]:

$$
\begin{aligned}
& G_{T}=\left(G_{b}+G_{d} A_{i}\right) R_{b}+G_{d}\left(1-A_{i}\right)\left(\frac{1+\cos \beta}{2}\right) \\
& {\left[1+f \sin ^{3}\left(\frac{\beta}{2}\right)\right]+G \rho_{g}\left(\frac{1-\cos \beta}{2}\right)}
\end{aligned}
$$

The energy produced by a photovoltaic panel is estimated from the values of the global irradiation on an inclined plane, the ambient temperature and the values of the photovoltaic panel manufacturer's data. It is given by [6]:

$$
E_{p v}=R_{p v} \cdot S_{p v} \cdot P_{f} \cdot H \cdot N
$$

The performance of the photovoltaic generator is represented by the following equation:

$$
\begin{aligned}
& R_{p v}=\eta_{r}\left\{1-\gamma\left(T_{c}-T_{S T C}\right\}\right. \\
& T_{C}=T_{a}+G_{i n c}\left(\frac{N O C T-20}{800}\right)
\end{aligned}
$$

\subsection{Distribution of wind Speeds and Energy Yielded by Wind Generator}

The Weibull function is used to characterise the distribution of wind frequencies during the study period and is defined as [7]:

$$
f(V)=\left(\frac{k}{A}\right)\left(\frac{V}{A}\right)^{k-1} \exp \left[\left(\frac{V}{A}\right)^{k}\right]
$$

Wind speeds $V_{\mathrm{m}}$ can be calculated according to Weibull's $\mathrm{K}$ and A parameters as indicated below:

$$
V_{m}=A \Gamma\left(1+\frac{1}{k}\right)
$$



follows [8]:

Wind power density of a site according to Weibull's probability density function can be expressed as

$$
P=\frac{1}{2} S_{e o l} \rho A^{3} \Gamma\left(1+\frac{3}{k}\right)
$$

where $S_{\text {eol }}$ is the area swept by the wind turbine blade $\left(\mathrm{m}^{2}\right)$ and $\mathrm{p}$ is air density $\left(1.225 \mathrm{~kg} / \mathrm{m}^{3}\right)$.

Once the wind power density is given, the energy yielded by the wind generator for a desired period can be calculated by [9]:

$$
\frac{E}{S_{\text {eol }}}=\frac{1}{2} \rho A^{3} \Gamma\left(1+\frac{3}{k}\right) \cdot T
$$

\subsection{Battery Size}

The storage capacity of batteries is determined according to the maximum required load (maximum monthly load) that is expressed by [10]:

$$
C_{\text {batt }, \text { tot }}=\frac{E_{L, m, \max }}{\eta_{\text {bat }} \cdot U_{b a t} \cdot P_{d d} \cdot N_{m}} \cdot N_{j a}
$$

The number of required batteries is determined according to the capacity of a battery unit $\mathrm{C}_{\mathrm{batt}, \mathrm{u}}$ as in the case of the surfaces of photovoltaic generators by taking by rounding up the full ratio value.

$$
N_{b a t t}=E N T\left[\frac{C_{b a t t, t o t}}{C_{b a t t, u}}\right]
$$

$S_{p v}$ and $S_{e o l}$ are the respective surfaces of the panel and the turbine able to produce a $100 \%$ coverage of the load during the least favourable month [11]:

$$
\begin{aligned}
& S_{p v}=\max \left(\frac{E_{d}}{E_{p v}}\right) \\
& S_{e o l}=\max \left(\frac{E_{d}}{E_{e o l}}\right)
\end{aligned}
$$

The total energy produced by the photovoltaic modules and wind turbines which supply the whole charge is expressed by:

$$
E_{d}=E_{p v} \cdot S_{p v}+E_{e o l} \cdot S_{e o l}
$$

By using the two renewable sources, the charge is divided into two parts. If the fraction of the charge supplied by the photovoltaic system is $\mathrm{f}$, then the complement of the charge which is (1-f) must be fed by the wind system. The limit values of $\mathrm{f}$ correspond to pure systems. In fact, $\mathrm{f}=1$ corresponds to a full utilization of the photovoltaic system and $\mathrm{f}=0$ represents a full utilization of the wind system.

The equations $(11,12$ ) become:

$$
\begin{aligned}
& E_{p v} \cdot S_{p v}=f \cdot E_{d} \\
& E_{e o l} \cdot S_{e o l}=(1-f) \cdot E_{d}
\end{aligned}
$$


The calculations are based on the monthly averages of each year respectively. The surfaces of the photovoltaic panels and rotor of wind turbine are determined from the monthly average values of each year calculated from $\overline{E_{p v}}$ and $\overline{E_{e o l}}$. The full charge is marked $E_{d}$ and the surfaces of the photovoltaic and rotor of wind are expressed through the following equations:

$$
\begin{aligned}
& S_{P V}^{S=1}=f \cdot \frac{\overline{E_{d}}}{\overline{E_{p v}}} \\
& S_{E O L}^{S=1}=(1-f) \cdot \frac{\overline{E_{d}}}{\overline{E_{E o l}}}
\end{aligned}
$$

the retained component of the surface $S_{i, u}(i=1)$ for the photovoltaic component and $(i=2)$ for the rotor of turbine component. The surface of the component unit $\mathrm{S}_{\mathrm{i}, \mathrm{u}}\left(\mathrm{S}_{\mathrm{pv}, \mathrm{u}}=0.34 \mathrm{~m}^{2}, \mathrm{~S}_{\mathrm{eol}, \mathrm{u}}=0.56 \mathrm{~m}^{2}\right)$ The retained surface is calculated according to the following equation:

$$
S_{i, u}^{S}=\text { Cte. } S_{i, u}
$$

With: Cte is a whole number close to a high degree of the ratio $\frac{S_{i}^{S}}{S_{i, u}}$ and 'S' is stands for the scenario.

\section{SYSTEM DESCRIPTION}

The system under study includes photovoltaic panels and/or wind turbines connected to the direct current bus (DC) and storage batteries. Each storage battery is connected in series to the 120V (DC) bus. A convertor connected into the alternative current bus (AC) is used to convert into alternative current the energy yielded by the photovoltaic panels, the wind turbines and the energy stored in batteries. The electricity generated by our system supplies the apartment. The energy not consumed after serving the charge is stored in the batteries.

The photovoltaic system produces a direct voltage which is stored in the battery after crossing a charge controller of the photovoltaic system. The wind turbine yields an alternative current which is converted into direct current and stored in the battery. A discharge load is also connected to the battery to deviate the extra load when the battery is fully loaded.

The diagram that groups together each possible component of the system is illustrated in Figure 5 [12].

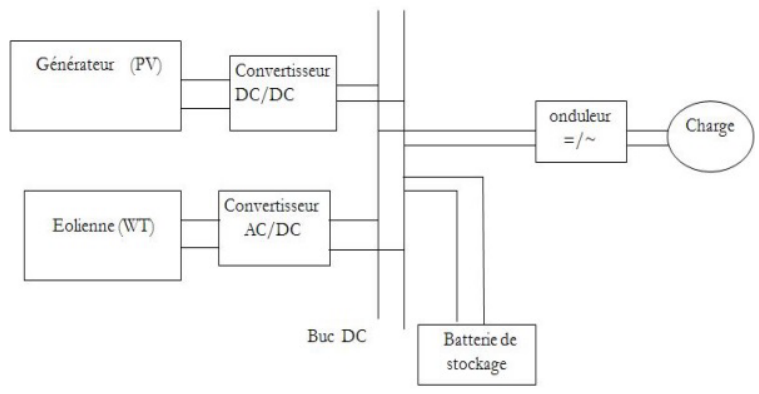

Figure 5. Flow diagram of the system

The technical specifications of the main components of the system are indicated in Table 4. 
Table 4. Technical Details of the System

\begin{tabular}{|c|c|}
\hline Parameters & Values \\
\hline Photovoltaic panels & Price:65.00€/panel \\
\hline Nominal capacity $(k W)$ & 0,05 \\
\hline Panel Performance (\%) & 13 \\
\hline Voltage $M p p(V)$ & 18 \\
\hline Intensity Mpp (A) & 2,78 \\
\hline Short-circuit current (A) & 3,16 \\
\hline Open-circuit voltage (V) & 22,2 \\
\hline Warranty (years) & 10 \\
\hline Size (length/width/height)(mm) & $630 \times 545 \times 25$ \\
\hline Weight (Kg) & 4 \\
\hline Life time (years) & 20 \\
\hline Wind turbine & Price: $2000.00 €$ /turbine \\
\hline rated capacity (W) & 1000 \\
\hline Maximum power (W) & 1500 \\
\hline Start speed $(\mathrm{m} / \mathrm{s})$ & 2 \\
\hline Nominal speed $(\mathrm{m} / \mathrm{s})$ & 10 \\
\hline Stop speed $(\mathrm{m} / \mathrm{s})$ & 55 \\
\hline Wind turbine efficiency (\%) & 96 \\
\hline Noise level (dB) & 45 \\
\hline Warranty (years) & 5 \\
\hline Life time (years) & 25 \\
\hline Weight $(\mathrm{Kg})$ & 78 \\
\hline Rotor length (m) & 2,8 \\
\hline Rotor width (m) & 2 \\
\hline Battery & Prix: $305.00 €$ /battery \\
\hline Nominal voltage $(V)$ & 12 \\
\hline Capacity (Ah) & 230 \\
\hline Maximum voltage (V) & 14,4 \\
\hline Starting current (A) & 1150 \\
\hline Charge voltage (\%) & 10 \\
\hline Series-connected batteries & 10 \\
\hline Life at $50 \%$ of discharge (cycle) & 200 \\
\hline Size (length/width/height)(mm) & $518 \times 276 \times 242$ \\
\hline Weight (Kg) & 56,75 \\
\hline Warranty (years) & 1 \\
\hline Convertor & Prix: $1000.00 €$ /convertor \\
\hline Maximum power (kW) & 1210 \\
\hline Maximum voltage (V) & 400 \\
\hline Voltage range $P V, M P P T(V)$ & $139-320$ \\
\hline Max input current (A) & 10 \\
\hline Nominal power $(k W)$ & 1000 \\
\hline Output current (A) & 5,6 \\
\hline Nominal voltage range (V) & $220-240 / 180-260$ \\
\hline Frequency range network $(\mathrm{Hz})$ & $50-60$ \\
\hline Maximum efficiency (\%) & 93 \\
\hline Size (length/width/height)(mm) & 434 x 295 x 214 \\
\hline Weight $(\mathrm{Kg})$ & 22 \\
\hline Noise level (dB) & 39 \\
\hline
\end{tabular}




\section{RESULTS AND DISCUSSION}

This part shows the influence of the characteristics of solar and wind energy resources on the sizing of the size and the efficiency of an electric power generation system. After entering the necessary data in the calculation program, he will execute several simulations by modifying parameters and determining optimal solutions. The result of the simulation shows the most feasible configuration of the energy system as well as the energy produced by each source. The results of the photovoltaic energy gathered are illustrated in Figure 6.

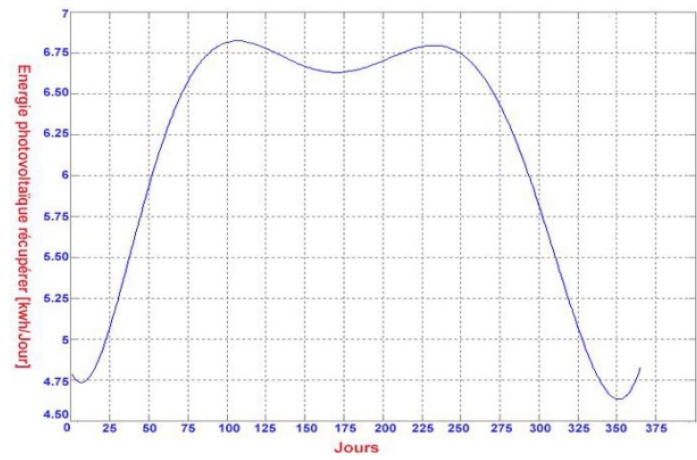

Figure 6. Solar photovoltaic energy received in the site on an inclined plane

The Figure 6 shows the variation profile of the solar voltaic energy collected from day to day during the year. Two maximum values can be distinguished: The energy collected on the 110th day reaches $6.87 \mathrm{kWh}$ and $6.80 \mathrm{kWh}$ on the 237th day. Figure 7.

The wind energy collected on the basis of daily wind speeds in the region of Tlemcen is shown in

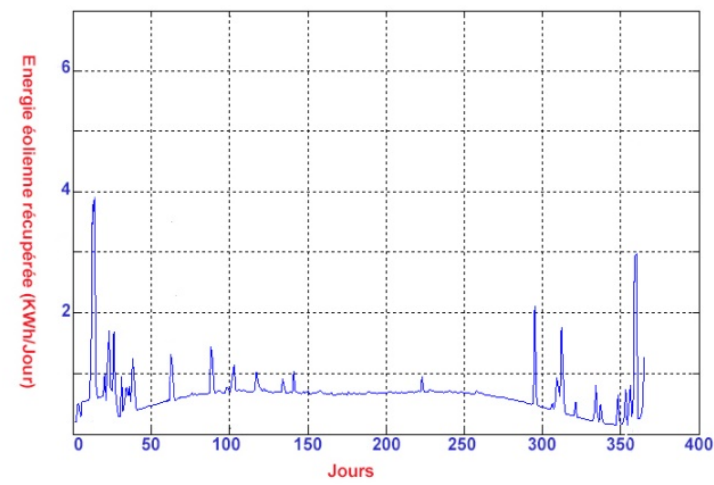

Figure 7. Daily wind energy collected in Tlemcen

Figure 7 shows that the months of January and December are the most profitable of the year when the recovered wind energy reaches the maximum value of: $14.2 \mathrm{kWh} / \mathrm{d}$. For the rest of the year, as the wind energy is very weak, this region resorts to more photovoltaic than wind electricity.

The wind rose and the distribution of wind speed frequencies are evaluated all year long to determine if the wind blows in one direction with a respective intensity all over the year. The annual results are shown in Figures 8-9.

The terminal values of " $\mathrm{k}$ " and " $\mathrm{A}$ " parameters are 1 and $2.42 \mathrm{~m} / \mathrm{s}$ respectively. Considering value "A" who is very low, which makes it very difficult to exploit the wind potential since all wind turbines start to produce from $2 \mathrm{~m} / \mathrm{s}$. The value of "K" is estimated at $1 \mathrm{~m} / \mathrm{s}$, this low wind density is not favorable to the continuous operation of the wind system for a whole day. Therefore, Tlemcen presents very weak conditions in term of wind resource. 
As regards the of the wind rose diagram shown in figure (8), it is noted that the direction of dominant winds is from the northern side of Tlemcen.

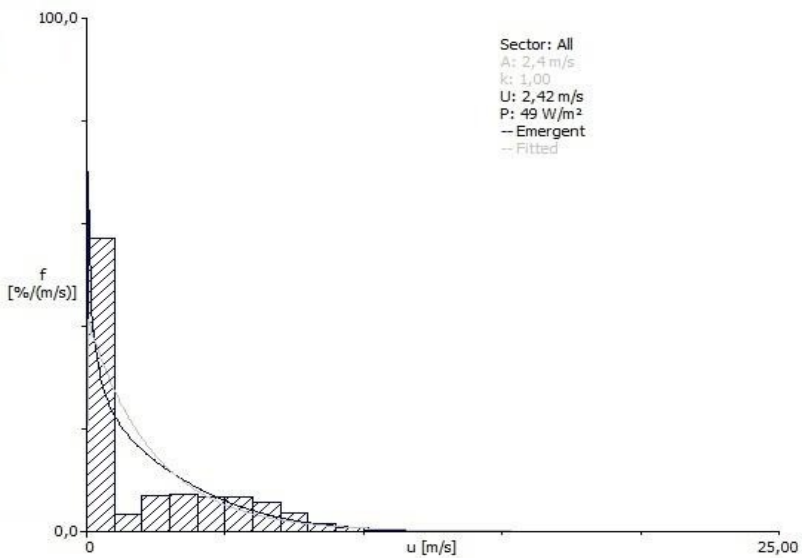

Figure 8. Wind speeds frequencies according to the Weibull distribution

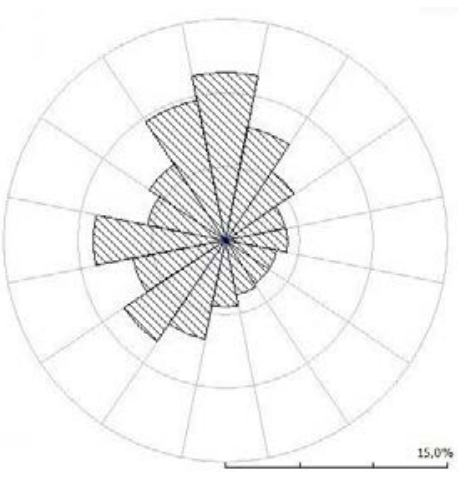

Figure 9. Diagram of the wind rose at $10 \mathrm{~m}$ height

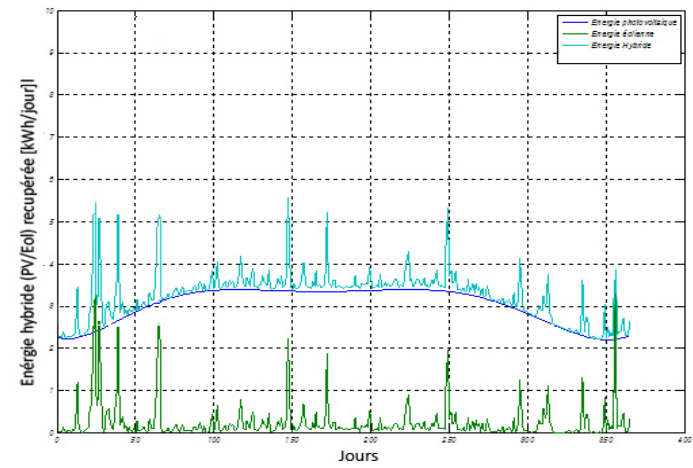

Figure 10. Hybrid energy (photovoltaic-wind) received

Figure 10 is interpreted for the following periods:

The 1st period: from the 1st day until the 90th day, the load of the apartment is fixed at 3,26kWh/d (See Table 3). This winter period has 8 deficit days that are: (1, 3, 5, 8, 10, 12, 15 and 16) days, this gives one day of autonomy since the days are not successive, so storage in the batteries is introduced to cover the load of the apartment.

The 2nd period: from the 91st day to the 274th day, the load of the apartment is fixed at $9.15 \mathrm{kWh} / \mathrm{d}$. This summer period does not include deficit days, the system operates normally without recourse to batteries, the energy produced is fairly constant in this period and reaches the maximum value of $5.6 \mathrm{KWh} / \mathrm{d}$.

The third period: from the 275th day until the end of the year, the load of the apartment is set at 3.26 $\mathrm{kWh} / \mathrm{d}$. This winter period has other deficit days that are: (235, 237, 239 and 242) days it gives one day of autonomy. Since the load demand is constant for each period, the results show that the most unfavourable month is when the ratio between solar irradiation and wind speed is minimum. According to the results, the worst month is the month of December.

\subsection{Calculating the Number of Batteries}

The number of days of autonomy is evaluated at one day (24 hours). The daily energy demand during this day is set at 3260 ah. The storage system will compensate the interruption of the power generation system. The electricity that comes out of the batteries does not come entirely to electrical devices: part is lost in the wires and during the conversion of current DC to AC by the converter, the amount of energy to be returned is $3.95 \mathrm{kWh}$. In order to have a longer life of the batteries, a maximum discharge depth of $50 \%$ is set, the 
capacity of the storage system will have to be $7.91 \mathrm{kWh}$, this leads to a quantitative number of 3 storage batteries during this deficit day.

The calculation program finds the best configurations of the power generation system that will generate enough or all of the energy at the apartment. The results of these configurations are shown in the Table 5.

Table 5. Optimum configurations

\begin{tabular}{ccc}
\hline Parameters & \multicolumn{2}{c}{ Optimum Configurations } \\
& Configuration A & Configuration B \\
\hline Photovoltaic system(KW) & 1,7 & 1,4 \\
Number of panels PV & 34 & 28 \\
Number of wind turbines & 0 & 1 \\
Number of batteries & 3 & 3 \\
Number of convertors & 1 & 1 \\
Total cost $(€)$ & 4125 & 5735 \\
\hline
\end{tabular}

Table 5 shows the two best retained configurations. The configuration (A) contains a purely photovoltaic system with a power of $1.7 \mathrm{~kW}$ and consists of 34 photovoltaic panels, 3 storage batteries, one converter and no contains wind generator. The surface of the photovoltaic panels represents $12.7 \mathrm{~m}^{2}$. The net present cost of this configuration is estimated at 4125 euro.

The second configuration (B) contains a hybrid wind and photovoltaic system. The number of photovoltaic panels is inferior to that of the configuration (A) and has 28 panels and represents $9.6 \mathrm{~m}^{2}$, generating a power of $1.4 \mathrm{~kW}$. The number of storage batteries and converters is the same as that of the configuration (A). Regarding the net present cost of this configuration, it is higher and estimated at 5735 euro.

\subsection{Production Result and Electric Consumption}

This part shows more details on the two configurations by comparing the energy produced and consumed annually of each configuration (kWh/year).

Figures 11-12 show the average monthly power production of each configuration.

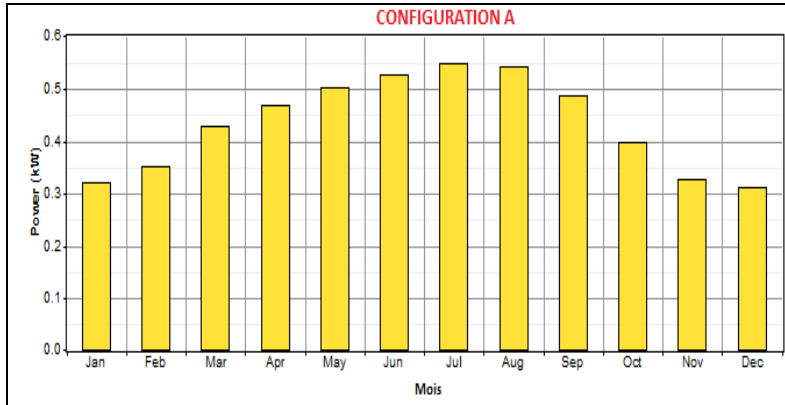

Figure 11. Average monthly power production of configuration 'A'

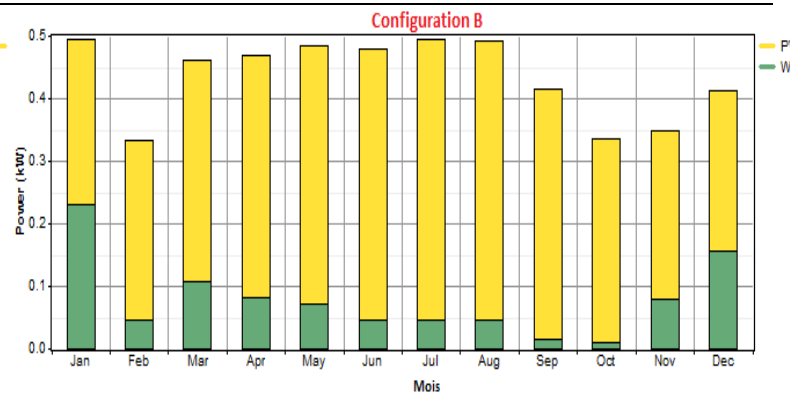

Figure 12. Average monthly power production of configuration 'B'

From Figure 11 it has been found that the production of electrical energy comes only from the photovoltaic system estimated at $3803 \mathrm{kWh} /$ year. The average hourly output is less than $0.4 \mathrm{~kW} / \mathrm{h}$ from November to February, unlike the other months of the year when this average is greater than or equal to 0.5 $\mathrm{kW} / \mathrm{h}$. The electrical energy consumed directly from the bus (AC) represents $1756 \mathrm{kWh} / \mathrm{year}$, the rest of the energy produced is stored in batteries so that it can be used during the night or in the deficit period in solar radiation and represents $1606 \mathrm{kWh} /$ year is $42.2 \%$ of the production of the pure photovoltaic system.

Figure 12 shows that the production of electrical energy from the photovoltaic/wind hybrid system is estimated at $3822 \mathrm{kWh} /$ year where $82 \%$ is generated by the photovoltaic panels and $18 \%$ of the wind system is respectively $3132 \mathrm{kWh} /$ year and $690 \mathrm{kWh} /$ year. The energy generated by the photovoltaic panels is much 
higher than that of the wind system during all the months of the year. The average hourly production in February, October and November is less than $0.4 \mathrm{~kW} / \mathrm{h}$ However, it can reach $0.5 \mathrm{~kW} / \mathrm{h}$ the other months of the year. The electrical energy consumed directly from the bus (AC) represents $1755 \mathrm{kWh} / \mathrm{year}$, the rest is stored in the batteries so that it can be used during the night or in the deficit period of the two energy sources and represents $1730 \mathrm{kWh} /$ year or $45.3 \%$ of the production of the hybrid system.

\subsection{Other Results of Configuration 'A'}

This part will discuss the behaviour of photovoltaic panels with storage during all the days of the year. Figure 13.

The annual energy produced by the photovoltaic system per day and throughout the year is shown in

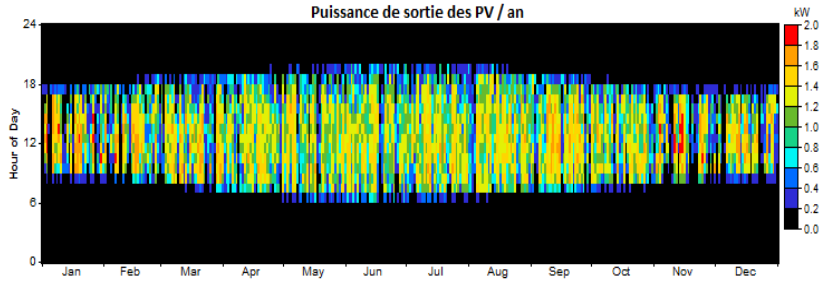

Figure 13. The daily energy produced by the PV during the year

According to Figure 13, the production is stable during all the days of the year and this between 6:00 and 19:00. The daily output is around $0.4 \mathrm{~kW}$ up to $1.2 \mathrm{~kW}$ continuously and can even reach $1.8 \mathrm{~kW}$ and very rarely $2 \mathrm{~kW}$ during the day. The production is zero during the night and represents $0 \mathrm{~kW}$. The hours of operation of the photovoltaic panels are evaluated at $4387 \mathrm{~h} /$ year.

Figure 14 shows the daily status of charging and discharging batteries throughout the year.

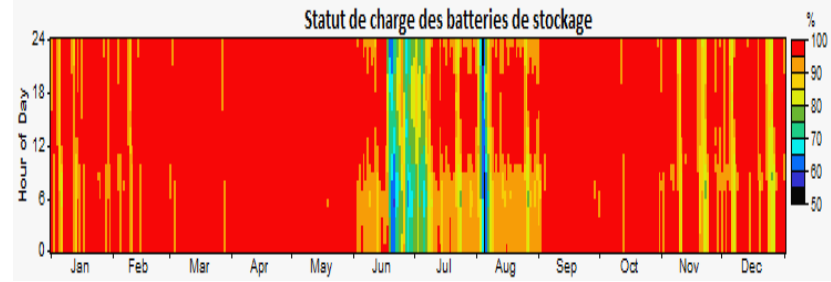

Figure 14. Daily status of charge and discharge of batteries during the year

Figure 14 shows that the batteries are always full during the year except during the summer period which lasts from June until August when it can reach a discharge depth estimated from 90\% to 65\%. In mid-July the battery discharge will reach the maximum of $50 \%$ for a few hours at night. The energy convertor operates fully all year long.

\subsection{Other Results of Configuration 'B'} the year.

This part will discuss the behaviour of the photovoltaic/wind hybrid system during all the days of

The annual energy produced by the photovoltaic system and the wind system each day of the year is shown respectively in Figure 15 and 16. 


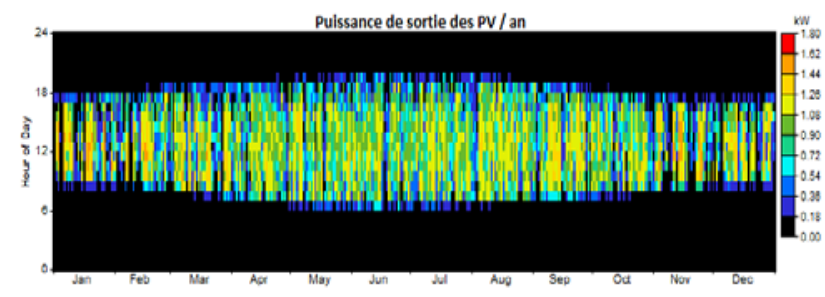

Figure 15. Daily energy produced by PV during the year

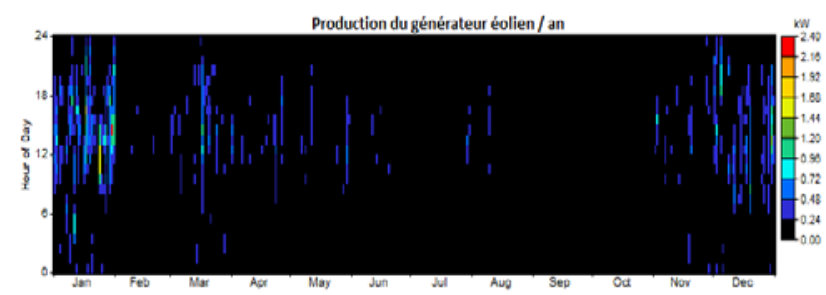

Figure 16. Daily energy produced by the wind turbine during the year

According to Figure 15 and 16, it has been noticed that the production of the photovoltaic system is dominant during the year whereas it is reduced during the months of January, November and December relative to the results of the configuration ' $\mathrm{A}$ '. this phenomenon is due to the presence of the wind generator that associates with the photovoltaic system. Nevertheless, wind generation is valid essentially only in December and January. It is estimated very low between 0.24 and $0.48 \mathrm{~kW}$. It reaches its maximum value of $2.23 \mathrm{~kW}$ during the middle of January. The hours of operation of the wind turbine are low. The batteries will have the same behaviour of the configuration (A) and the converter works fully during the year.

Therefore, the configuration "A" is better than the configuration "B" taking into account the total net cost of the investment and which equals respectively 4125 euro against 5735 euro.

\section{CONCLUSION}

The study conducted in this article leads to deduce optimal configurations of photovoltaic system and/or wind power generation with storage in batteries, in order to provide electricity to a residential apartment autonomous and away from the conventional power grid in Tlemcen, Algeria.

The methodology and optimization models used to determine the best energy production system are valid for any site in the world and especially for small power sites. The results obtained show the inefficiency of the wind energy potential in this non windy site, from which the exploitation of the only one of a pure photovoltaic system is recommended while avoiding the exploitation of a photovoltaic / wind hybrid system.

\section{REFERENCES}

[1] Ministère de l'Energie et des Mines. (2007). Guide des Energies Renouvelables , Algérie.

[2] R.MAOUEDJ. (2005). Application de l'énergie photovoltaïque au pompage hydraulique sur les sites de Tlemcen et de Bouzaréah. Mémoire de Magister, Université de Tlemcen, Algérie.

[3] http://www.infoclimat.fr

[4] D.SAHEB-KOUSSA, M. BELHAMEL et K.BENFERHAT, Contribution à l'étude théorique du comportement d'un système hybride (éolien- photovoltaïque- diesel) de production d'électricité sans interruption, Afrique SCIENCE, Vol. $05 \mathrm{~N}^{\circ} 1$, pp. 23 - 38, ISSN 1813-548X, 2009.

[5] Reindl DT, Beckman WA, Duffie JA. (1990). Evaluation of hourly tilted surface radiation models. Sol Energy, Vol. 45, n 1, p. 9-17.

[6] M.A. EL HADIDY. (2002). Performance Evaluation of Hybrid (Wind/Solar/Diesel) Power Systems. Renewable Energy, Vol. 26, p. $401-413$.

[7] Khahro SF, Tabbassum K, Soomro AM, Dong L, Liao X. (2014). Evaluation of wind power production prospective and Weibull parameter estimation methods for Babaurband, Sindh Pakistan. Energy Convers Manage, Vol. 78, $\mathrm{n}^{\circ}$ 956, p. 67.

[8] Akpinar EK, Akpinar S. (2005). An assessment on seasonal analysis of wind energy characteristics and wind turbine characteristics. Energy Convers Manage, Vol. 46. N 1848, p. 67. 
[9] Keyhani A. Ghasemi-Varnamkhasti M. Khanali M. Abbaszadeh R. (2010). An assessment of wind energy potential as a power generation source in the capital of Iran. Tehran. Energy, Vol. 35, p. 188-201.

[10] O.GERGAUD. (2002). Modélisation énergétique et optimisation économique d'un système de production éolien et photovoltaïque couplé au réseau et associé à un Accumulateur. Thèse de Doctorat en Electrotechnique, Ecole Normale Supérieure de Cachan, France.

[11] C. PROTOGEROPOUIOS, B.J. BRINKWORTH and R.H. MARSHALL. (1997). Sizing and Techno Economical Optimization for Hybrid Solar Photovoltaic/Wind Power Systems with Battery Storage . Int. J. Energy Res., Vol. 21, p. 465-479,

[12] H. BELGHITRI, Modélisation, simulation et optimisation d'un système hybride éolien photovoltaïque . Mémoire de magister, Université de Tlemcen, 2011. 